\title{
Helicobacter pylori and Telomerase Activity in Intestinal Metaplasia of the Stomach
}

\author{
II Kwun Chung, M.D., Kyu Yoon Hwang, M.D.*, In Ho Kim, M.D., \\ Hong Soo Kim, M.D., Sang Heum Park, M.D., Moon Ho Lee, M.D., \\ Chang Jin Kim, M.D. ${ }^{\dagger}$ and Sun Joo Kim, M.D.
}

\author{
Division of Gastroenterology, Departments of Internal Medicine, Preventive Medicine* \\ and Pathology ${ }^{\dagger}$, Soonchunhyang University Chonan Hospital, \\ Soonchunhyang University Medical College, Chonan, Korea
}

\begin{abstract}
Background: Helicobacter pylori (H. pylori) has been considered a definitive carcinogen in gastric cancer. Telomerase is activated in gastric cancer and some premalignant gastric lesions, including intestinal metaplasia (IM). In this study, we evaluated the relationships of both $H$. pylori infection and telomerase activity with endoscopic and histologic features in $I M$. The effects of $H$. pylori eradication on endoscopic, histologic and biochemical changes were evaluated.

Methods: Endoscopic biopsies were obtained from 43 patients with $I M$ for rapid urease, histologic and telomerase tests. The endoscopic and histologic features, $H$. pylori infection and telomerase were assessed. After $H$. pylor eradication, 15 patients were re-evaluated and compared after 4 months.

Results: Thirty-four (79.1\%) patients were infected with $\mathrm{H}$. pylori. The incidence of $H$. pylori infection was borderline correlated to the severity of $I M$ ( $p=0.076)$. Telomerase was elevated in eight (18.6\%) patients. Telomerase tends to be high in subtype III and endoscopic grade III of $I M$. After $H$. pylori eradication, endoscopic extent $(p=0.039)$ and histologic severity ( $p=0.074)$ showed improvements, and telomerase decreased significantly $(p=0.0001)$.

Conclusion: Our data suggest that telomerase is associated with the severity and extent of $I M$ and that $H$. pylori eradication improves the endoscopic and histologic features in $I M$, and decreases telomerase activity. $H$. pylori eradication can be considered one of the methods to prevent gastric cancer in patients with $H$. pylori-infected IM. Further long-term and large-scaled study will be needed.
\end{abstract}

Key Words : Telomerase, Helicobacter pylori, Intestinal metaplasia, Gastric cancer

\section{INTRODUCTION}

Gastric cancer is one of the most common types of cancer worldwide" ${ }^{1)}$. Despite some improvement in its treatment, the 5 -year survival rate of gastric cancer is still low. The prevalence of intestinal metaplasia (IM)

Address reprint requests to : / Kwun Chung, M.D.,

Division of Gastroenterology, Department of Internal Medicine, Soonchunhyang University Chonan Hospital, 23-20 Bongmyung-dong, Chonan, Choongnam 330-100,

Korea.E-mail : euschung@sparc.schch.co.kr

Some of the results in this paper were presented at Digestive Disease Week (DDW), Atlanta, May 2001. is closely related to $H$. pylori infection ${ }^{2}$. Furthermore, chronic gastritis due to $H$. pylori infection may progress to IM and even gastric cancer ${ }^{3-5)}$. H. pylori-induced inflammation facilitates gastric carcinogenesis by increasing the rate of cell replication, decreasing the concentration of ascorbic acid and inducing DNA damage via reactive oxygen species ${ }^{6,7)}$. Both environmental and genetic factors are crucial in the multistage model of gastric tumorigenesis $^{3}$. A preliminary observation has suggested that both $\mathrm{IM}$ and $H$. pylori infection are important targets in the prevention of gastric cancer ${ }^{8)}$.

Telomerase, located at the distal end of human chromosomes, comprises simple, repetitive and G-rich 
hexameric sequences (TTAGGG), and is vital for chromosomal stability and replication. Telomerase is a ribonucleoprotein polymerase that adds telomeric sequences onto the ends of the chromosome to compensate for the DNA end-replication problem. Thus, this activity is strongly associated with cell immortalization and carcinogenesis, and its presence is elevated in $85 \%$ of human cancers, including those associated with the stomach, colon, breast, bladder, prostate, liver, lung and ovary. The measurement of telomerase activity may become a diagnostic tool for cancer ${ }^{9}$. However, telomerase activity can also be found in precancerous lesions, such as $\mathrm{IM}^{10)}$.

In this study, we evaluated the relationships of both $\mathrm{H}$. pylori infection and telomerase activity with endoscopic and histologic features in IM. The effects of $H$. pylori eradication on endoscopic, histologic and biochemical changes were evaluated.

\section{PATIENTS AND METHODS}

This study involved 43 patients who, between January 1999 and June 2000, were diagnosed with IM without any gastroenterologic diseases by an upper gastrointestinal endoscopic examination at a gastrointestinal endoscopy unit of Soonchunhyang University Chonan hospital. Thirtyfour of these patients were diagnosed as having $H$. pylori infection. Eight patients exhibited elevated telomerase activity. Twenty-three of the patients with $H$. pylori infection were treated with an $H$. pylori eradication regimen and fifteen of them were able to be followed up for changes in endoscopic, pathologic and telomerase results after 4 months of complete therapy.

\section{1) Gastric tissue sampling by upper gastrointestinal endoscopy}

Six gastric specimens were obtained by endoscopic biopsy of the IM lesion. Two of these specimens were fixed in 10\% buffered formalin, embedded in paraffin and sectioned, and then one was stained with hematoxylin -eosin ( $H$ \& E) and/or WarthinStarry silver stain for detecting $\mathrm{H}$. pylori. The other specimens were stained using the high-iron diamine (HID)/alcian blue (AB) technique to differentiate acidic mucin into sialomucins (blue) and sulfomucins (brown-black) ${ }^{11}$. The other two specimens were used to detect telomerase activity. One set of gastric tissue from the antrum and body was obtained and used for the Campylobacter Like Organism
(CLO) test and monitored for color changes for up to 24 $h$ at room temperature.

\section{2) Grading of intestinal metaplasia}

Endoscopic grades were classified according to the degree and pattern of mucosal elevation: I, granular; II, nodular; III, irregular or confluent. The extent of IM, as assessed endoscopically, was graded as follows: I, confined to antrum; II, extending to lower body; III, extending to upper body and fundus. Histologic grading is classified by $\mathrm{HID} / \mathrm{AB}$ and $\mathrm{H} \& E$ staining. Metaplastic lesions were classified into three subtypes: type I, complete IM characterized as resembling the normal intestinal epithelium; type II, incomplete IM expressing sialomucins but not sulfomucin; and type III, incomplete $\mathrm{IM}$ expressing sulfomucins. If $\mathrm{IM}$ of more than one subtype was present in a given sample, the case was assigned to the least mature subtype, as proposed previously ${ }^{2}$.

\section{3) Telomerase assay}

Protein extracts were obtained and a telomerase activity assay was performed as described previously ${ }^{12}$. One to three milliliters of tissue extract $(1 \sim 50 \mu \mathrm{g}$ of total protein) was subjected to a modified, semiquantitative telomeric repeat amplification protocol, which included an internal telomerase assay standard ${ }^{13)}$. A polymerase chain reaction $(\mathrm{PCR})$ was performed using a thermal cycler (DNA engine: Peltier thermal cycler, MJ Research, Waltham, Mass., USA) using primer elongation at $25^{\circ} \mathrm{C}$ for $10 \mathrm{~min}$ and inactivation at $94^{\circ} \mathrm{C}$ for $5 \mathrm{~min}$. Thirty-three PCR cycles were performed which consisted of $94^{\circ} \mathrm{C}$ for $30 \mathrm{~s}, 50^{\circ} \mathrm{C}$ for $30 \mathrm{~s}$ and $72^{\circ} \mathrm{C}$ for $90 \mathrm{~s}$. After hybridization using digoxin and a telomeric repeat sequence, the absorbancy was measured at $450 \mathrm{~nm}$ by a microtiter plate (ELISA) reader. Negative and positive controls were read using a PCR ELISA kit (TeloTAGGG Telomerase PCR ELISA ${ }^{\text {PLUS }}$, Roche, Nutley, N.J., USA). The final value was obtained by subtraction of the mean of the absorbance readings of the negative controls from the absorbance readings of the samples (i.e., AsAs.o). Samples are considered as telomerase-positive if the difference in absorbance (A) is higher than two times the background activity. Quantification of telomerase activity was determined as the relative telomerase activity using a formula provided in the PCR ELISA kit.

\section{4) $H$. pylori eradication and follow-up}

The H. pylori eradication regimen was administrated to 
15 patients with $H$. pylori infection for 2 weeks as $20 \mathrm{mg}$ omeprazole, $1000 \mathrm{mg}$ amoxicillin and clarithromycin $500 \mathrm{mg}$ twice per day. Four months later we performed endoscopic, histologic, and biochemical evaluations.

\section{5) Statistical analysis}

Statistical analysis was performed using the Stata program (Release 5.0; Stata, College Station, Texas, USA). The chi-square or Fishers exact test was utilized to analyze differences in the proportions of $H$. pylori infection status or telomerase activity in the endoscopic and histologic findings. The Wilcoxon signed rank test was utilized when comparing paired samples. $p$ values less than 0.05 were considered to be statistically significant.

\section{RESULTS}

\section{1) General profiles}

The mean (SD) age of the subjects was 52.2 (11.1)

Table 1. General profiles of study subjects $(H$. pylori, Helicobacter pylori)

\begin{tabular}{|c|c|c|}
\hline Chara & Classification & N (\%) \\
\hline \multicolumn{2}{|c|}{ Age in years: mean (SD) } & $52.2(11.1)$ \\
\hline \multirow[t]{2}{*}{ Sex } & Male & $29(67.4)$ \\
\hline & Female & $14(32.6)$ \\
\hline \multirow[t]{7}{*}{ Histology } & Subtype & \\
\hline & I & $17(39.5)$ \\
\hline & ॥ & $21(44.8)$ \\
\hline & $\begin{array}{l}\text { III } \\
\text { Severity grade }\end{array}$ & 5 (11.6) \\
\hline & Mild & $18(41.9)$ \\
\hline & Moderate & $9(20.9)$ \\
\hline & Severe & $16(37.2)$ \\
\hline \multirow[t]{7}{*}{ Endoscopy } & Pattern & \\
\hline & Granular & $11(25.6)$ \\
\hline & Nodular & $24(55.8)$ \\
\hline & Confluent & $8(18.6)$ \\
\hline & Degree of extent & $9(209)$ \\
\hline & $\|$ & $14(32.6)$ \\
\hline & III & $20(46.5)$ \\
\hline \multirow[t]{3}{*}{ Chemistry } & H. pylori infection & \\
\hline & Yes & $34(79.1)$ \\
\hline & No & $9(20.9)$ \\
\hline \multirow[t]{4}{*}{ Telomerase } & Activity & \\
\hline & Positive & $8(18.6)$ \\
\hline & Negative & $35(81.4)$ \\
\hline & Total & $43(100)$ \\
\hline
\end{tabular}

years and $29(67.4 \%)$ of them were male. The nodular pattern and grade-III extent was prevalent (24, 55.8\%; 20, 46.5\%; respectively) in the endoscopic findings. The prevalence of subtype $\|(21,44.8 \%)$ and mild grade (18, $41.9 \%$ ) was highest in histologic findings. Thirty-four (79.1\%) patients showed $H$. pylori infection and eight $(18.6 \%)$ had elevated telomerase activity (Table 1$).$

\section{2) Clinical features and H.pylori infection}

The granular type was significantly higher in $\mathrm{H}$. pylori infection $(11,32.4 \%$ vs $0,0 \%, p=0.03$ ) and the increase in grade-I extent was borderline significant $(9,26.5 \%$ vs $0,0 \% p=0.076$ ) in endoscopic findings. However, $H$. pylori infection rates were not significantly different according to histologic subtype $(p=0.473)$ or severity $(p=0.704)$ (Table 2).

\section{3) Clinical features and telomerase activity}

Telomerase activity was detected in eight (18.6\%) patients. Telomerase activity showed a high tendency in subtype III of IM, but without statistical significance $(p=0.179)$. There was no relation between histologic severity of $\mathrm{IM}$ and telomerase activity $(p=0.731)$. There were no significant relationships between endoscopic pattern and telomerase activity, but telomerase activity showed a high tendency in a wide extent of IM (Table 3).

Table 2. Clinical features of intestinal metaplasia (IM) according to $H$. pylori infection

\begin{tabular}{ccccc}
\hline Clinical & Classification & $\begin{array}{c}\text { H. pylori } \\
\text { positive } \\
(\mathrm{N}=34)\end{array}$ & $\begin{array}{c}\text { H. pylori } \\
\text { negative } \\
(\mathrm{N}=9)\end{array}$ & $p$ value \\
\hline Histology & Subtype & & & \\
& I & $13(30.2)$ & $4(44.4)$ & 0.473 \\
& II & $16(47.1)$ & $5(55.6)$ & \\
& III & $5(14.7)$ & $0(0)$ & \\
& Severity grade & & & \\
& Mild & $14(41.2)$ & $4(44.4)$ & 0.704 \\
& Moderate & $8(23.5)$ & $1(11.1)$ & \\
& Severe & $12(35.3)$ & $4(44.4)$ & \\
\hline Endoscopy & Pattern & & & \\
& Granular & $11(32.4)$ & $0(0)$ & 0.03 \\
& Nodular & $19(55.9)$ & $5(55.6)$ & \\
Confluent & $4(11.7)$ & $4(44.4)$ & \\
& Degree of extent & & & \\
I & $9(26.5)$ & $0(0)$ & 0.076 \\
II & $12(35.3)$ & $2(22.2)$ & \\
III & $13(38.2)$ & $7(77.8)$ & \\
\hline
\end{tabular}


Table 3. Clinical features of IM according to telomerase activity

\begin{tabular}{lcccc}
\hline Clinical & Classification & $\begin{array}{c}\text { Telomerase } \\
\text { positive } \\
(\mathrm{N}=8)\end{array}$ & $\begin{array}{c}\text { Telomerase } \\
\text { negative } \\
(\mathrm{N}=35)\end{array}$ & $p$ value \\
\hline Histology & Subtype & & & \\
& I & 2 & 14 & 0.179 \\
& II & 4 & 17 & \\
& III & 2 & 3 & \\
& Severity grade & & & \\
& Mild & 4 & 14 & 0.731 \\
& Moderate & 2 & 7 & \\
& Severe & 2 & 3 & \\
\hline Endoscopy & Pattern & & & \\
& Granular & 2 & 9 & 0.871 \\
& Nodular & 4 & 20 & \\
& confluent & 2 & 6 & \\
& Degree of extent & & & \\
I & 1 & 8 & 0.159 \\
II & 2 & 12 & \\
III & 5 & 15 & \\
\hline
\end{tabular}

Table 4. Comparisons between initial and follow-up conditions after $H$. pylori eradication in 15 patients with IM

\begin{tabular}{cllll}
\hline Clinical & Classification & \multicolumn{1}{c}{ Change } & N & $p$ value* \\
\hline Histology & Subtype & Downgraded & 8 & \\
& & Same & 4 & 0.671 \\
& Upgraded & 3 & \\
& Severity & Improvement & 10 & \\
& Same & 1 & 0.074 \\
& Aggravation & 4 & \\
\hline Endoscopy & Pattern & Improvement & 5 & \\
& & Same & 9 & 0.151 \\
& Aggravation & 1 & \\
& Extent & Improvement & 6 & \\
& Same & 8 & 0.039 \\
& Aggravation & 1 & \\
\hline
\end{tabular}

* by Fishers exact test


Figure 1. The endoscopic pattern of IM. Granular is defined as type I (A), nodular as type II (B) and confluent as type III (C).
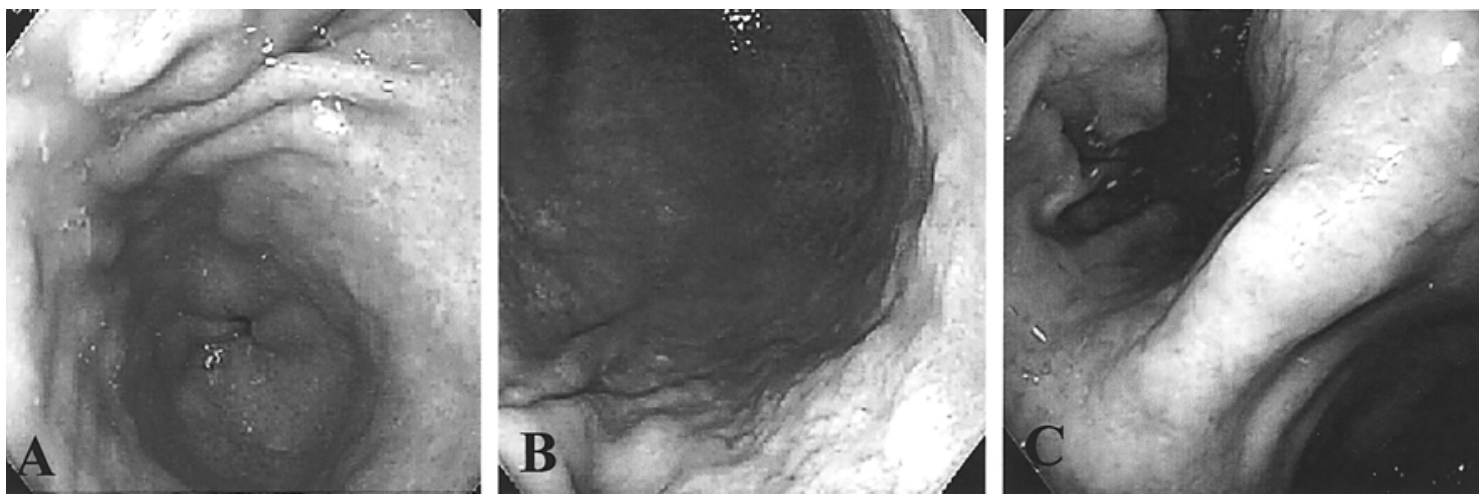

Figure 2. The endoscopic extent of IM. IM in antrum is defined as grade I (A), extending to lower body as grade II (B) and extending to upper body and fundus as grade III (C). 

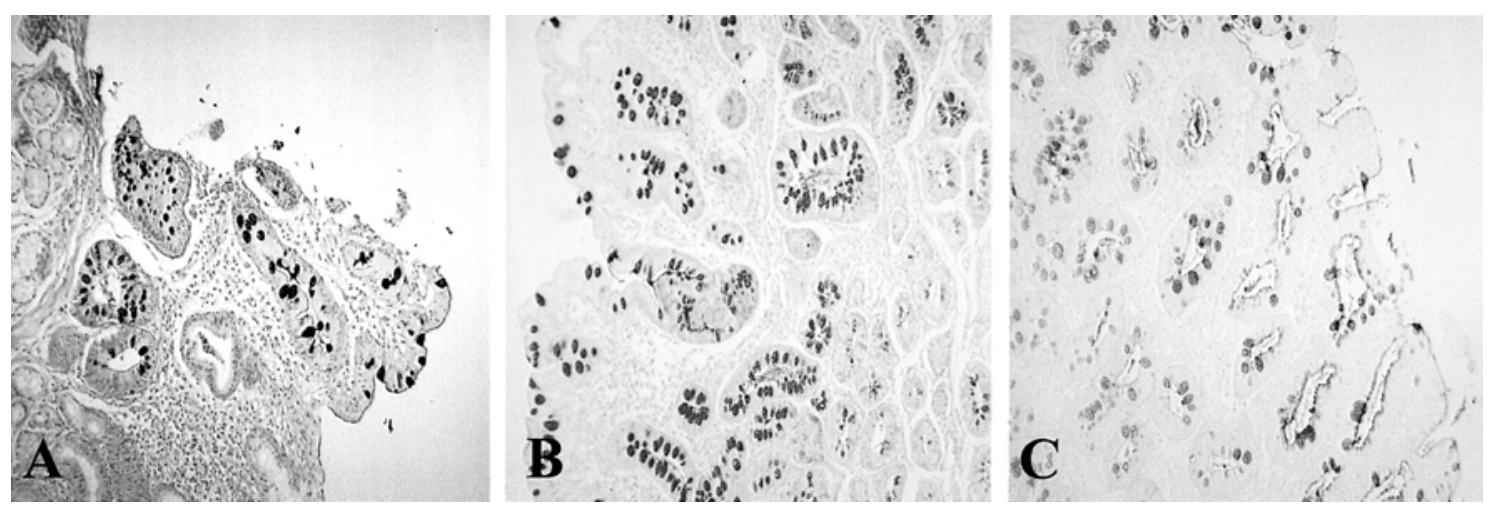

Figure 3. The histologic subtype of IM. Type I is incomplete IM characterized as resembling the normal intestinal epithelium (A), type II is complete IM expressing sialomucins but not sulfomucins (B) and type III is incomplete IM expressing sulfomucins (C).

\section{4) Follow-up after $H$. pylori eradication}

We performed repeat endoscopic and histologic examinations and evaluated telomerase activity in 15 patients to compare the quantitative changes in the activities (relative telomerase activity). Eight and ten out of 15 patients were downgraded or improved according to histologic subtype $(p=0.671)$ and severity $(p=0.074)$, respectively. In endoscopy, five and six patients showed improvement of pattern $(p=0.151)$ and extent $(p=0.039)$, respectively. There was a significant difference in extent grading between initial and follow-up after $H$. pylori eradication according to endoscopic findings $(p=0.039)$ (Table 4). Telomerase activity showed a significant decrease in this period ( $1321.5 \pm 870.8$ vs $373.2 \pm 560.68$, $p=0.0001$ ) (Figure 1).

\section{DISCUSSION}

Telomerase activity in humans has been detected in germ lines and tumor tissues as well as in established cultured-cell lines ${ }^{14)}$. In normal somatic cells, the absence or low expression of telomerase is thought to result in progressive telomeric shortening with each cell division. Therefore, it has been proposed that reactivation of telomerase is a critical step in tumorigenesis. The expression of telomerase may occur at different stages of cancer progression, depending on the type of malignancy ${ }^{15-19)}$.

Telomerase activity has been detected in approximately $35 \%$ of noncancerous lesions, such as gastric $1 \mathrm{M},{ }^{10)}$ although the level is generally lower than in cancerous tissue. In addition, genetic alterations, such as $p 53^{20)}$ and

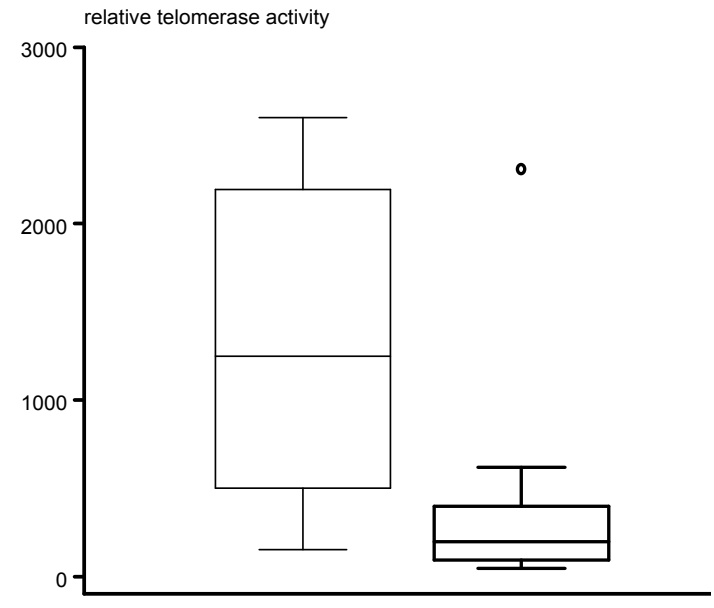

Figure 4. Box plots comparing telomerase activity between initial and follow-up conditions in 15 patients after $H$. pylori eradication

APC gene mutations ${ }^{211}$, are found in IM and gastric cancer. These genetic changes and the activation of telomerase in IM and so-called precancerous lesions may contribute to the carcinogenic process in intestinal gastric cancers ${ }^{20}$. Furthermore, detection of telomerase activity in both cancer and IM suggests that telomerase activation is an early event in stomach carcinogenesis. In our study, telomerase activity was detected in $18.6 \%$ of patients.

IM is the common endoscopic feature that occurs at an average age of 14 years after superficial and/or atrophic gastritis. The occurrence of chronic atrophic gastritis has a complex relationship to $H$. pylori infection, 
genetics, diet, drugs, smoking, alcohol, high salt intake, vitamin- $C$ deficiency and environmental factors. $I M$ is the replacement of gastric mucosal cells with intestinal cells (including goblet cells). Regression of $\mathrm{IM}$ after $\mathrm{H}$. pylori eradication is debatable in many histologic studies ${ }^{22-31)}$, and studies on endoscopic changes are also limited.

We randomly classified the endoscopic grade and extent of IM according to the nature of gross severity. Through the classification, we assessed the relationship between endoscopic features and $H$. pylori infection or telomerase activities and we evaluated the significance of these endoscopic findings on the basis of histology and molecular biology. We also observed the changes of these endoscopic classifications and histologic and molecular biologic changes as detailed markers of precancerous lesions after $H$. pylori eradication. In our study, changes in the grade of the pattern of $\mathrm{IM}$ were not statistically significant and the extent of IM tended to decrease. These changes represent the possibility of regression of endoscopic findings. The $H$. pylori infection rate was high in the endoscopic granular type which was suspected as being a relatively low-grade lesion. The H. pylori infection rate had a tendency to be higher in the grade-I extent of IM than grade-II or III extent. These results suggest indirectly that the $H$. pylori infection rate is high in the early stages of $\mathrm{IM}$, and suggest that $H$. pylori cannot survive for long enough to allow migration from the antrum to the upper body by the progression of IM. Among the eight patients with telomerase activity, there was no significant relationship between the endoscopic pattern of $\mathrm{IM}$ and telomerase activity, but telomerase activity tended to be detected in grade-III extent. These findings suggest that the endoscopic extent of IM represents the duration of $H$. pylori infection and premalignant tendency of $\mathrm{IM}$.

The relationships between the histologic characteristics of $\mathrm{IM}$ and $H$. pylori infection have been studied extensively. In the present study, the $H$. pylori infection rate did not differ significantly with histologic subtype and severity. Telomerase activity tends to be high in subtype III of IM; this subtype is known to be more precancerous in nature than other histologic types in pathologic studies. ${ }^{32)}$ The number of subjects in our study is too small to allow us to say definitively that subtype III of IM has a precancerous nature at the molecular level. There was no relation between the histologic severity of $\mathrm{IM}$ and telomerase activity. The nature of the precancerous lesion did not depend on histologic severity, but subtype is more important in the prediction of cancerous changes in
IM. The histologic subtype was changed in $73.3 \%$ of cases with IM and the severity of IM tended to decrease. Metaplastic changes disappeared in $20 \%$ of cases. Taken together, these observations suggest the possibility of reversibility of $\mathrm{IM}$ after $H$. pylori eradication.

Our study suffered from some limitations associated with the use of endoscopic biopsies, but these are unavoidable in a clinical study. However, we used special staining techniques to maximize our ability to assess the pattern and extent of $\mathrm{IM}$, and we recorded the lesion site to allow re-examining of the same site by endoscopic biopsy. Another problem is that a relatively small number of subjects was included in this study to induce a statistically significant result for comparing the relationship among various factors, which needs subsequent more studies to confirm the clinical significance of relating factors in patients with $\mathrm{IM}$.

The changes in quantitation of telomerase activities (relative telomerase activity) was significantly decreased in patients regardless of the positivity of the telomerase activity. These results suggest that $H$. pylori eradication is needed in $H$. pylori-infected patients with IM, especially those that have endoscopic findings of widespread and histologic subtype III IM.

To conclude, in IM a widespread endoscopic lesion and histologic subtype III produces a tendency for high telomerase activity, which is a predictable marker of malignant changes. $H$. pylori eradication improved the endoscopic and histologic features and decreased telomerase activity. We carefully suggest that $H$. pylori eradication can be considered one of the methods to prevent gastric cancer in patients with $H$. pylori-infected IM. Further long-term and large scaled study will be needed.

\section{REFERENCES}

1) Parkin DM, Pisani P, Fearly J. Estimates of the worldwide incidence of eighteen major cancers in 1985. Int J Cancer 54:594-606, 1993

2) Rugge $M$, Cassaro $M$, Leandro G, Baffa R, Avellini C, Bufo P, Stracca V, Battaglia G, Fabiano A, Guerini A, Di Mario F. Helicobacter pylori in promotion of gastric carcinogenesis. Dig Dis Sci 41:950-955, 1996

3) Corea P. Human gastric carcinogenesis: a multistep and multifactorial process. Cancer Res 52:6735-6740, 1992

4) Dobrilla G, Benvenuti S, Amplatz S, Zancanella L. Chronic gastritis, intestinal metaplasia, dysplasia and Helicobacter pylori in gastric cancer: putting the pieces 
together. Ital J Gastroenterol 26:449-458, 1994

5) Stemmermann GN. Intestinal metaplasia of the stomach: a status report. Cancer 74:556-564, 1994

6) Sobala GM, Schorah CJ, Shires S, Lynch DA, Gallacher B, Dixon MF, Axon AT. Effect of eradication of Helicobacter pylori on gastric juice ascorbic acid concentrations. Gut 34:1038-1041, 1993

7) Bechi $P$, Balzi M, Becciolini A, Maugeri A, Raggi CC, Amorosi A, Dei R. Helicobacter pylori and cell proliferation of the gastric mucosa: possible implications for gastric carcinogenesis. Am J Gastroenterol 91:271-276, 1996

8) Caselli M. Helicobacter pylori, intestinal metaplasia and gastric cancer: histopathological point of view. Am J Gastroenterol 91:1473-1475, 1996

9) Shay JW, Bacchetti S. A survey of telomerase activity in human cancer. Eur J Cancer 33:787-791, 1997

10) Kuniyasu $H$, Domen $T$, Hamamoto $T$, Yokozaki $H$, Yasui W, Tahara H, Tahara E. Expression of human telomerase RNA is an early event of stomach carcinogenesis. Jpn J Cancer Res 88:103-107, 1997

11) Lev R. The mucin histochemistry of normal and neoplastic gastric mucosa. Lab Invest 14:2080-2100, 1965

12) Kim NW, Piatyszek MA, Prowse KR, Harley CB, West MD, Ho PL, Coviello GM, Wright WE, Weinrich SL, Shay JW. Specific association of human telomerase activity with immortal cells and cancer. Science 26:1115-1117, 1995

13) Wright WE, Shay JW, Piatyszek MA. Modifications of a telomeric repeat amplification protocol (TRAP) result in increased reliability, linearity and sensitivity. Nucleic Acids Res 23:3794-3795, 1995

14) Holt SE, Shay JW, Wright WE. Refining the telomerase hypothesis of aging and cancer. Nat Biotechnol 14:836-839, 1996

15) Hiyama E, Yokoyama T, Hiyama K, Ishikawa T, Matsuura $\mathrm{Y}$. Length of telomeric repeat in neuroblastoma: correlation with prognosis and other biological characteristics. Jpn J Cancer Res 83:159-164, 1992

16) Hiyama K, Hiyama E, Ishioka S, Yamakido M, Inai K, Gazda AF, Piatyszek MA, Shay JW. Telomerase activity in small-cell and non-small-cell lung cancers. I Natl Cancer Inst 87:895-902, 1995

17) Mao L, El-Naggar AK, Fan $Y-H$, Lee JS, Lippman SM, Kayer S, Lotan R, Hong WK. Telomerase activity in head and neck squamous cell carcinoma and adjacent tissues. Cancer Res 56:5600-5604, 1996

18) Hiyama $E$, Kodama $T$, Shinbara $K$, Iwao $T$, Itoh $M$, Hiyama K, Shay JW, Matsuura Y, Yokoyama T. Telomerase activity is detected in pancreatic cancer but not in benign tumors. Cancer Res 57:326-331, 1997

19) Chadeneau C, Hay K, Hirte HW, Galligner S, Bacchetti S. Telomerase activity associated with acquisition of malignancy in human colorectal cancers. Cancer Res

\section{5:2533-2536, 1995}

20) Ochiari A, Yamauchi $Y$, Hirohashi S. p53 mutations in the non-neoplastic mucosa of the human stomach showing intestinal metaplasia. Int J Cancer 69:28-33, 1996

21) Nishimura $\mathrm{K}$, Yokozaki $\mathrm{H}$, Haruma $\mathrm{K}$, et al. Alterations of the APC gene in carcinoma cell lines and precancerous lesions of the stomach. Int J Oncol 7:587-592, 1995

22) Haruma K, Mihara M, Kamada T, Komoto K, Yoshihara M, Sumii K, Kajiyama G. Eradication of Helicobacter pylori reverses intestinal metaplasia in patients with severe atrophic gastritis. Gastroenterology 112:A142, 1997

23) Annibale B, Marignani M, Azzoni C, D'Ambra G, Caruana P, D'Adda T, Delle Fave G, Bordi C. Helicobacter pylori infection. Helicobacter 2:57-64, 1997

24) El-Omar EM, Oien K, El-Nujumi A, Gillen D, Wirz A, Dahill S, Williams C, Ardill JE, McColl KE. Helicobacter pylori infection and chronic gastric acid hyposecretion. Gastroenterology 113:15-24, 1997

25) van der Hulst RWM, van der Ende, Dekker FW, Ten Kate FJ, Weel JF, Keller JJ, Kruizinga SP, Dankert J, Tytgat GN. Effect of Helicobacter pylori eradication on gastritis in relation to cagA: a prospective 1-year follow-up study. Gastroenterology 113:25-30, 1997

26) Genta RM, Lew GM, Graham DY. Changes in the gastric mucosa following eradication of Helicobacter pylori. Mod Pathol 6:281-289, 1993

27) Witteman EM, Mravunac M, Becx MJCM, Hopman WP, Verschoor JS, Tytgat GN, de Koning RW. Improvement of gastric inflammation and resolution of epithelial damage one year after eradication of Helicobacter pylori. J Clin Pathol 48:250-256, 1995

28) Uemura N, Mukai T, Okamoto S, Yamaguchi S, Mashiba H, Taniyama K, Sasaki N, Haruma K, Sumii K, Kajiyama G. Effect of Helicobacter pylori eradication on subsequent development of cancer after endoscopic resection of early gastric cancer. Cancer Epidemiol Biomarkers Prev 6:639 $-642,1997$

29) Griffiths AE, Thursz MR, Walker MM. Do intestinal metaplasia and gastric atrophy reverse after $H$. pylori? Gut 41:A48, 1997

30) Calya R, Carles B, de Mascarel A, Zerbib F, Lamouliatte H. Long-term follow-up of chronic gastritis after persistent Helicobacter pylori eradication in duodenal ulcer patients. Gastroenterology 108:A68, 1995

31) Satoh K, Kimura K, Takimoto T, Kihira K, Taniguchi $Y$. Long-term follow-up of gastric atrophy and intestinal metaplasia of patients who received and did not receive anti-Helicobacter pylori therapy. Gastroenterology 112:A280, 1997

32) Filipe Ml. Mucins in the human gastrointestinal epithelium: a review. Invest Cell Pathol 2:195-216, 1979 